\title{
Microvascular obstruction persistence after early-reperfused myocardium infarction by CMR: analysis of first week and six months after STEMI
}

\author{
Amarino C Oliveira $\mathrm{Jr}^{1 *}$, Denise M Moreira ${ }^{1}$, Carlos E Rochitte ${ }^{2}$, Suzana A Silva ${ }^{3}$, Hans F Dohmann ${ }^{3}$ \\ From 2011 SCMR/Euro CMR Joint Scientific Sessions \\ Nice, France. 3-6 February 2011
}

\section{Introduction}

Detection of microvascular obstruction (MO) with gadolinium first-pass perfusion (FP) and late gadolinium enhancement (LGE) MRI predicts outcomes of STEMI patients. Previous data indicate the presence of MO early after MI correlates to worse prognosis and left ventricular (LV) remodeling. Nonetheless, FP and early hypoenhancement on LGE may persist after reperfused STEMI for a variable period of time.

\section{Purpose}

We investigate whether the persistence of $\mathrm{MO}$ by CMR was related to worse LV remodeling at 6 month after STEMI.

\section{Methods}

We retrospectively analyzed 27 patients admitted with successfully reperfused STEMI and with infarct size $>10 \%$ of LV mass, who were enrolled in a stem cell trial. Baseline MRI was performed after the successful percutaneous coronary reperfusion, during first week, and repeated three and six months in the follow up. CMR exam included cine-MR using SSFP, FP and LGE acquisitions. Infarct size, LV volumes, mass and ejection fraction were measured by planimetry. Presence of hypoenhanced areas on LGE or perfusion defects on FP images within the infarct area were interpreted as MO. Patients were classified as absent MO (group 1), with MO on first CMR only (transient MO, group 2) and with $\mathrm{MO}$ on both studies (persistent MO, group 3). ANOVA was used to compare LV parameters at 6 month within the groups.

'Pro Cardiaco Hospital, Rio de Janeiro, Brazil

Full list of author information is available at the end of the article

\section{Results}

From 27 patients, 6 were in group 1, 8 in group 2, and 13 in group 3. LV ejection fraction at six month was significantly lower in persistent $\mathrm{MO}$ group compared to transient and absent $\mathrm{MO}(43.6 \pm 9.7 \%$ vs $47.1 \pm 7.9 \%$ vs 62.5 $\pm 15.7 \%, \mathrm{p}=0.006$ by ANOVA, $\mathrm{p}<0.05$ for group 1 vs 2 or 3 by Bonferroni sub-test). The percent increase in LVEF from baseline to 6 month was also lower for group 3 than for group 2 or $1(0.9 \pm 18.9 \%$ vs. $9.5 \pm 28.8 \%$ vs. $48.4 \pm 50.0 \%$, $\mathrm{p}=0.02)$. EDV was not statistically higher in group 3 compared to 2 and $1(156.7 \pm 46.5 \mathrm{ml}$ vs. $134.7 \pm 48.6 \mathrm{ml}$ vs. 130.0 $\pm 26.9 \mathrm{ml}, \mathrm{p} \mathrm{ns})$. Infarct size was larger in persistent $\mathrm{MO}$ group compared to the other 2 groups $(32.9 \pm 9.5 \%$ vs. 27.2 $\pm 14.3 \%$ vs. $18.8 \pm 10.2 \%$ of LV mass, $\mathrm{p}<0.05$ )

\section{Conclusions}

Persistence of microvascular obstruction defined as firstpass perfusion defect or early hypoenhancement core within the infarct was associated to worse left ventricular ejection fraction, remodeling and myocardial infarction. The correlation of MO persistence with prognostic surrogates, such as ventricular function and infarct size, warrants further investigation on the influence of MO persistence on the clinical events and prognosis.

\section{Author details}

'Pro Cardiaco Hospital, Rio de Janeiro, Brazil. ${ }^{2}$ Heart Institute -InCorUniversity of Sao Paulo Medical School, Sao Paulo, Brazil. ${ }^{3}$ Teaching and Research Center of Pro Cardiaco Hospital/Procep, Rio de Janeiro, Brazil.

Published: 2 February 2011

doi:10.1186/1532-429X-13-S1-P157

Cite this article as: Oliveira et al: Microvascular obstruction persistence after early-reperfused myocardium infarction by CMR: analysis of first week and six months after STEMI. Journal of Cardiovascular Magnetic Resonance 2011 13(Suppl 1):P157. 